\title{
Effect of niclosamide on the tegumental surface of Haplorchis taichui using scanning electron microscopy
}

\author{
K. Kumchoo ${ }^{1,2 *}$, C. Wongsawad ${ }^{1}$, P. Vanittanakom ${ }^{3}$, J.Y. Chai ${ }^{4}$ and \\ A. Rojanapaibul ${ }^{1}$ \\ ${ }^{1}$ Department of Biology, Faculty of Science, Chiang Mai University, Chiang \\ Mai 50200, Thailand: ${ }^{2}$ Faculty of Arts and Sciences, Prince of Songkla \\ University, Surat Thani Campus, Surat Thani 84100, Thailand: \\ ${ }^{3}$ Department of Pathology, Faculty of Medicine, Chiang Mai University, \\ Chiang Mai 50200, Thailand: ${ }^{4}$ Department of Parasitology and Institute of \\ Endemic Diseases, College of Medicine Seoul National University, Seoul \\ 110-799, Korea
}

\begin{abstract}
The effect of niclosamide on the tegument of adult Haplorchis taichui (Trematoda: Heterophyidae) exposed in vitro was observed by scanning electron microscope. Adult worms were incubated in Tyrode's solution containing 0.01, $0.1,1.0$, and $10 \mu \mathrm{g} \mathrm{ml}^{-1}$ of niclosamide for $30 \mathrm{~min}, 1,6,12$ and $24 \mathrm{~h}$. Control groups were incubated in Tyrode's solution without niclosamide and worms remained active until $24 \mathrm{~h}$. In $0.01 \mu \mathrm{g} \mathrm{ml}^{-1}$ of niclosamide, worms showed slightly active movements up to $1 \mathrm{~h}$ after incubation, while in $0.1 \mu \mathrm{g} \mathrm{ml}^{-1}$ solution a few worms showed only slightly active movements after $30 \mathrm{~min}$. Tegumental changes were determined by scanning electron microscopy. Swelling and blebbing of the tegument were observed on both ventral and dorsal sides. After longer periods, extensive swelling and blebbing of the tegument became more severe and there was a loss of the apical plasma membrane in some regions. Empty spine sockets occurred, and small perforations penetrated the basal lamina, followed by some lesions. Destruction of both surfaces was more pronounced on the posterior compared with the anterior regions.
\end{abstract}

\section{Introduction}

Haplorchis taichui is a small heterophyid intestinal fluke of fish-eating birds and mammals, and is an occasional parasite of humans (Faust \& Nishigori, 1926; Yamaguti, 1958). Humans acquire infections from eating raw or undercooked freshwater fish containing metacercariae of H. taichui. Cyprinid fish are an important intermediate host of this fluke. Haplorchis taichui infects various fish that are part of the human diet in northeast and northern

*E-mail: kan_kumchoo@yahoo.com
Thailand (Kliks \& Tantachamrun, 1974; Srisawangwong et al., 1997; Sukontason et al., 1999; Kumchoo et al., 2005).

Treatment of $H$. taichui is still a great problem and there is a high prevalence of $H$. taichui infection in the northern part of Thailand. The pathogenicity of worm infections has been reported from humans in Lampang Province, northern Thailand. Three heavily infected cases presented mucosal ulceration, mucosal and submucosal haemorrhages, fusion and blunting of villi, crypt hyperplasia, chronic inflammation, and fibrosis of the submucosa (Sukontason et al., 2005). The drugs of choice for treatment of this parasite, such as praziquantel, have been reported by many investigators (Scholz et al., 1991; Pungpak et al., 1998; Radomyos et al., 1998). Niclosamide is effective in 
the treatment of many kinds of trematode and cestode infections. This drug inhibits oxidative phosphorylation in the mitochondria of cestodes and has low side-effects because it is not absorbed from the gastrointestinal tract (Katz, 1986). Only a few cases of nausea, vomiting, diarrhoea, abdominal pain and dizziness were reported from some patients infected with Fasciolopsis buski and treated with niclosamide (Suntharasamai et al., 1974; Garcia, 2001; Anon., 2003). Niclosamide at a dosage of $6 \mathrm{~g}$ over 3 alternate days has been recommended for Heterophyes heterophyes infection (Khalil \& Rifaat, 1964) and $100-125 \mathrm{mg} \mathrm{kg}^{-1}$ for Metagonimus yokogawai infection (Rim, 1975). Also, niclosamide has been used to treat Diplozoon paradoxum and Gyrodactylus aculeati parasitizing the gills and skin of fish (Schmahl \& Taraschewski, 1987). This drug inhibits the uptake of glucose by the helminth, stops the production of its energy and can cause a paralytic effect on the worm. Niclosamide works by killing worms which are then passed in the stool. Occasionally worms cannot be collected after treatment because they are destroyed in the intestine of the host (Anon., 2003).

Little is known on the effect of drugs against $H$. taichui. Apart from spine damage and swollen basal spines, H. taichui appear to be resistant to praziquantel (Scholz et al., 1991). However, a $100 \%$ cure was found with niclosamide at a dose of $40 \mathrm{mg} \mathrm{kg}^{-1}$ body weight of mice (Sukontason et al., 2000). Albendazole has also been used in $H$. taichui infections, with a $100 \%$ cure at $40 \mathrm{mg} \mathrm{kg}^{-1}$ (Waikagul et al., 2003). Scanning electron microscopy has proved to be a useful tool for evaluating surface changes to flukes in general resulting from anthelmintic action. This is the first morphological study of the effects of niclosamide on $H$. taichui. The sequence of changes in the tegumental surface of adult $H$. taichui after in vitro exposure to various concentrations of niclosamide is described using scanning electron microscopy.

\section{Materials and methods}

Encysted metacercariae of Haplorchis taichui were obtained from naturally infected cyprinid fish (Heinecorhynchus siamensis) collected from Chiang Mai, northern Thailand. Encysted metacercariae were isolated by $1 \%$ (w/v) pepsin solution (pepsin 1:2500 Sigma ${ }^{\circledR} 1 \mathrm{~g}: \mathrm{NaCl}$ solution $99 \mathrm{ml}$ : hydrochloric acid $1 \mathrm{ml}$ ), pH 0.29-0.70, for $2 \mathrm{~h}$ at $37^{\circ} \mathrm{C}$. The digested material was passed through graded sieves, rinsed with $0.85 \%$ (w/v) $\mathrm{NaCl}$, and metacercariae were collected and examined under a stereo microscope. Three day-old chicks (Gallus gallus domesticus) were experimentally fed with approximately 1000 metacercariae. At the end of day 7 post-infection, adult worms were collected from the small intestine by the Baermann technique. Worms were washed in Tyrode's solution and used immediately for the experiment. A stock solution of niclosamide was prepared by dissolving $500 \mathrm{mg}$ of niclosamide (Hexane ${ }^{\circledR}$, Thailand) in $5 \mathrm{ml}$ of absolute ethanol and diluting this stock solution with distilled water to give a concentration of $50 \mu \mathrm{g} \mathrm{ml}^{-1}$. Niclosamide was prepared in various concentrations of $0.01,0.1,1.0$ and $10.0 \mu \mathrm{g} \mathrm{ml}^{-1}$. For each experiment, $5 \mathrm{ml}$ of solution and 100 active worms were introduced to each
Petri dish and incubated at $37^{\circ} \mathrm{C}$, including the control group with Tyrode's solution without niclosamide. After $30 \mathrm{~min}, 1,6,12$ and $24 \mathrm{~h}$-treated worms were washed three times in $0.1 \mathrm{M}$ phosphate buffer, $\mathrm{pH}$ 7.2. The movement of worms was observed and recorded under a stereo microscope. For scanning electron microscopy, treated worms were fixed in $2.5 \%(\mathrm{w} / \mathrm{v})$ glutaraldehyde at $4^{\circ} \mathrm{C}$ for $24 \mathrm{~h}$ and post-fixed with $1 \%$ osmium tetroxide for $2 \mathrm{~h}$. They were dehydrated in a graded alcohol series, dried in a critical-point dryer, gold-coated, and observed under a Dual Stage DS-130C and a JEOL-JSM2001LV scanning electron microscope.

\section{Results \\ Activity study}

Niclosamide was effective against $H$. taichui after in vitro treatment. One hundred active worms were treated in each experiment. Exposure of worms to $0.01 \mu \mathrm{g} \mathrm{ml}^{-1}$ of niclosamide after $30 \mathrm{~min}$ showed 3 active, 62 slightly active and 35 inactive worms and, $1 \mathrm{~h}$ later, 7 worms were slightly active and 93 worms were inactive. In $0.1 \mu \mathrm{g} \mathrm{ml}^{-1}$ of niclosamide solution after $30 \mathrm{~min}$, only 5 of 100 worms were slightly active and all worms were inactive after $1 \mathrm{~h}$. On the other hand, worms exposed to 1.0 and $10.0 \mu \mathrm{g} \mathrm{ml}^{-1}$ of niclosamide were all inactive after $30 \mathrm{~min}$. Control groups in Tyrode's solution showed active and slightly active worms over a $24 \mathrm{~h}$ (table 1$)$.

\section{Scanning electron microscopy}

Niclosamide caused progressive alterations to the tegumental surface of $H$. taichui and the degree of damage was correlated with the concentration of drug and exposure times.

\section{Control groups: Tyrode's solution}

The surface morphology of the tegument appeared normal, covered with scale-like multi-pointed spines and numerous sensory papillae. The tegument in the anterior region of worms is densely covered with large spines, which decrease in size and number posteriorly (fig. 1A-D).

\section{Treatment with $0.01 \mu \mathrm{g} \mathrm{ml^{-1 }}$ niclosamide}

In worms observed after $30 \mathrm{~min}$ and $1 \mathrm{~h}$, most of the tegument and sensory papillae on both surfaces retained a normal topography. After 6 and $12 \mathrm{~h}$ the surface became swollen with the development of small blebs and in some areas the spines, which appeared sunken, were supported by swellings on the tegument (fig. 2A). In some specimens after $12 \mathrm{~h}$, the tegument surrounding the oral sucker showed areas of erosion (fig. 2B). After 24h, the margin and base of each spine had begun to erode (fig. 2C) and numerous blebs had ruptured to produce further erosion of the tegument and spines (fig. 2D).

\section{Treatment with $0.1 \mu \mathrm{g} \mathrm{ml^{-1 }}$ niclosamide}

After $30 \mathrm{~min}$, although the sensory papillae remained unaffected, the surface showed signs of erosion with swelling of the tegument around the spines (fig. 3A). 
Table 1. Activity of Haplorchis taichui after incubation with concentrations ranging from 0.01 to $10 \mu \mathrm{g} \mathrm{ml}^{-1}$ of niclosamide.

\begin{tabular}{lccccc}
\hline & \multicolumn{5}{c}{ Incubation time } \\
\cline { 2 - 6 } $\begin{array}{l}\text { Drug concentration } \\
\left(\mu \mathrm{g} \mathrm{ml}^{-1}\right)\end{array}$ & $30 \mathrm{~min}$ & $1 \mathrm{~h}$ & $6 \mathrm{~h}$ & $12 \mathrm{~h}$ & $24 \mathrm{~h}$ \\
\hline 10.0 & - & - & - & - & - \\
1.0 & - & - & - & - & - \\
0.1 & $5^{*}$ & - & - & - & - \\
0.01 & $3^{* *} / 62^{*}$ & $7^{*}$ & - & - & - \\
Control & $100^{* *}$ & $100^{* *}$ & $100^{* *}$ & $88^{* *} / 12^{*}$ & $74^{* *} / 26^{*}$
\end{tabular}

100 active worms were used for each experiment.

**Active movement (1-5s per time); *slightly active movement (6-10 s per time); inactive ( $>10 \mathrm{~s}$ no movement).

After $1 \mathrm{~h}$, blebs of various sizes appeared above the ventrogenital sac which was more severely affected than other parts. Some blebs had collapsed and shrivelled, and some spine sinking had occurred (fig. 3B-C). After 6 and $12 \mathrm{~h}$, the blebs had increased in number with some blebs being in the process of disrupting (fig. 3C inset). By $12 \mathrm{~h}$, spines around the ventrogenital sac and in the mid-body to posterior region became eroded (fig. 3D) and after $24 \mathrm{~h}$, extensive blebbing had occurred and surface was completely swollen (fig. 3E). Some worms had lost the apical plasma membrane on both the ventral and dorsal surfaces in the middle to posterior regions, exposing empty spine sockets. The tegument on both surfaces showed similar changes (fig. 3E-F).

\section{Treatment with $1.0 \mu \mathrm{g} \mathrm{ml}^{-1}$ niclosamide}

After $30 \mathrm{~min}$, spherical blebs appeared on the tegument, heavily between the oral sucker and ventrogenital sac (fig. 4A) and after $1 \mathrm{~h}$, extensive blebbing occurred on the body surface (fig. 4B). Most of the tegumental surface was very swollen and the spines appeared sunken. Six hours after exposure, the surface blebs had become more widespread and in some cases severe, especially on the surface between the spines (fig. 4C-D). Some blebs had ruptured to form tegumental lesions, resulting in the surface beginning to slough off (fig. 4D). After $12 \mathrm{~h}$, the number of blebs and lesions had increased resulting in damage and loss of the tegumental surface and empty

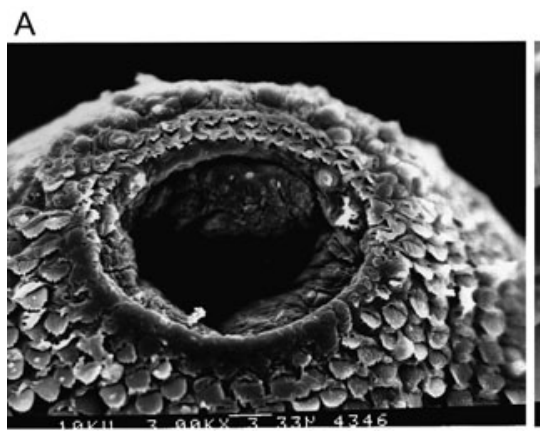

B
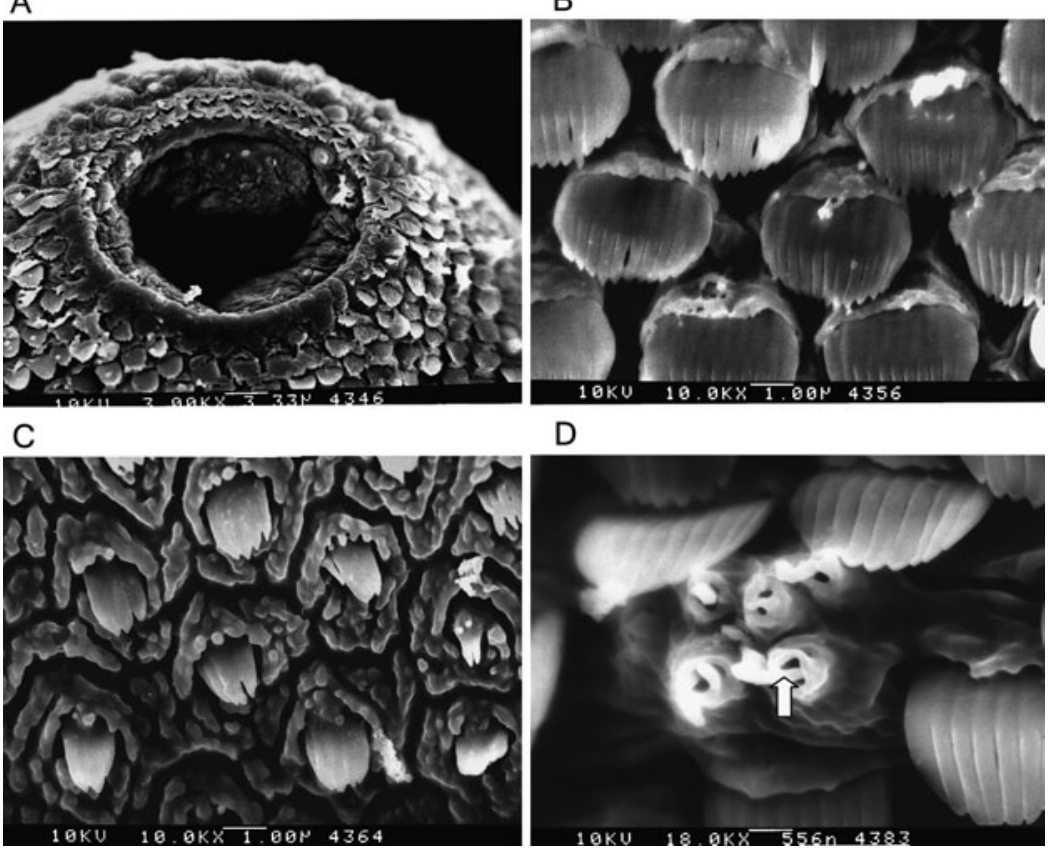

D

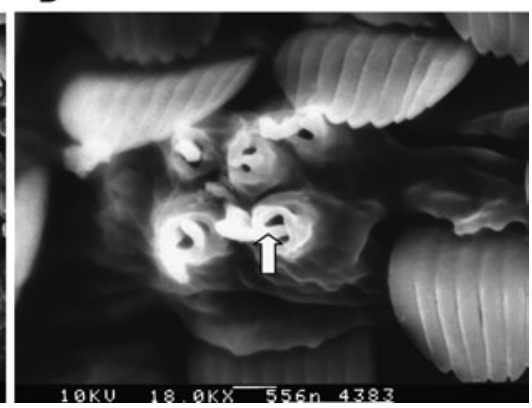

Fig. 1. Tegumental surface of adult Haplorchis taichui, $24 \mathrm{~h}$ after incubation in Tyrode's solution. A, Surface around the oral sucker ( $\times 3000)$; B, anterior region with large spines $(\times 10,000)$; C, posterior region with smaller size and number of spines $(\times 10,000)$; $\mathrm{D}$, the sensory papillae (arrowed) $(\times 18,000)$. 

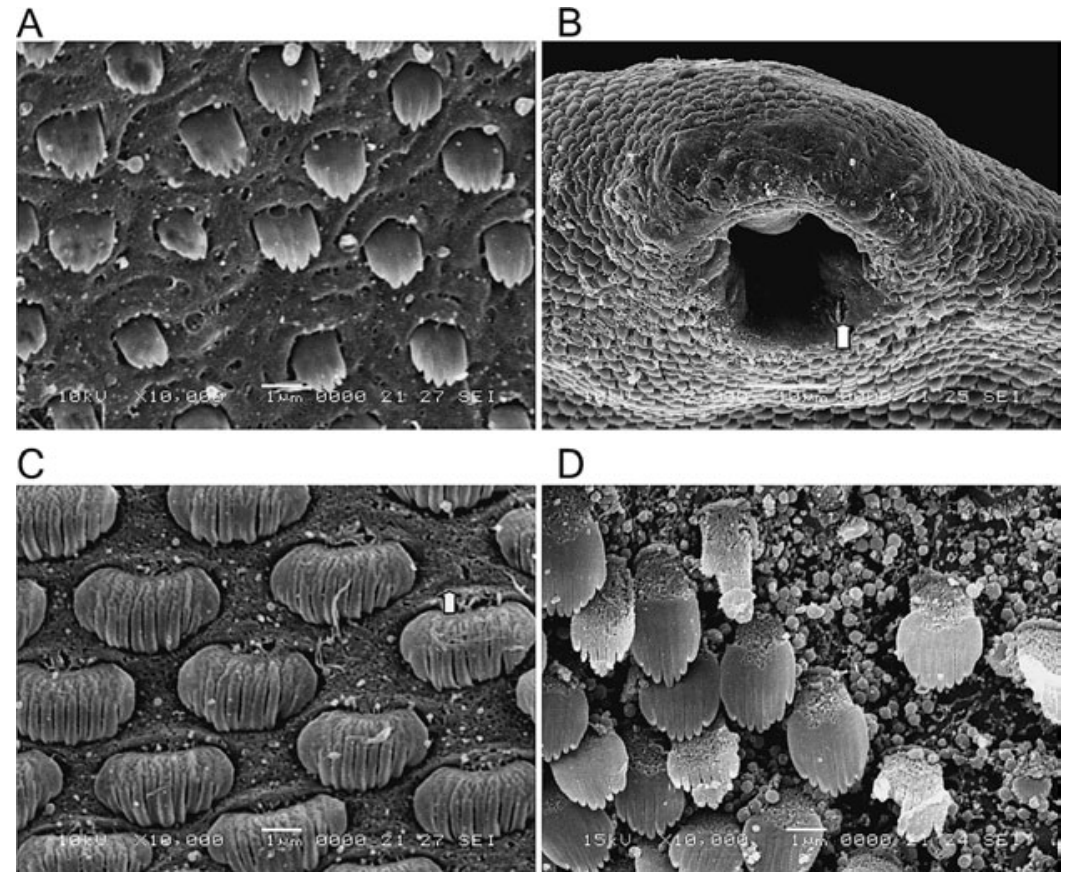

D

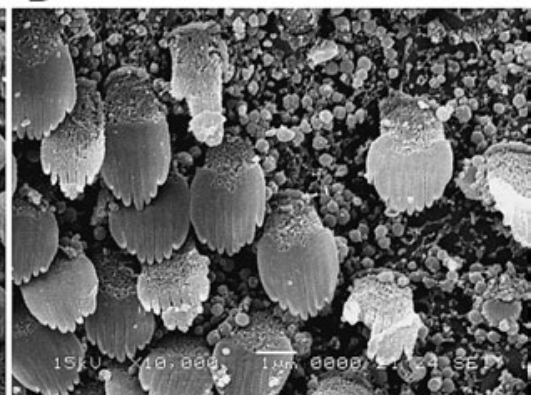

Fig. 2. Tegumental surface of adult Haplorchis taichui after incubation in $0.01 \mu \mathrm{g} \mathrm{ml}^{-1}$ niclosamide solution. A, Surface is swollen and covered with small blebs after $6 \mathrm{~h}(\times 10,000)$; B, damage on the surface around the oral sucker with the occurrence of lesions (arrowed) after $12 \mathrm{~h}(\times 2000)$; C, spine damage and lesions (arrowed) at the base of spines after $24 \mathrm{~h}(\times 10,000)$; $\mathrm{D}$, numerous small blebs resulting in some lesions and erosion of spines after $24 \mathrm{~h}(\times 10,000)$.

spine sockets appearing in the middle to posterior region of the body (fig. $4 \mathrm{E}-\mathrm{F}$ ). After $24 \mathrm{~h}$, severe damage to the tegument occurred, with the loss of the apical plasma membrane from both ventral and dorsal surfaces, leaving empty spine sockets (fig. 4F). More severe damage occurred in the posterior region of the body with numerous small perforations occurring in areas where the tegument had been removed (fig. 4F-G) and most sensory papillae had ruptured (fig. $4 \mathrm{H})$.

\section{Treatment with $10.0 \mu \mathrm{g} \mathrm{ml}^{-1}$ niclosamide}

After $30 \mathrm{~min}$, most worms exhibited swelling of the tegument around the spines and after $1 \mathrm{~h}$, some blebs which had burst causing lesions were scattered over the inter-spine areas (fig. 5A-B). After $6 \mathrm{~h}$, more blebs had ruptured and the surface was eroded on both the ventral and dorsal surfaces (fig. 5C). In some specimens, spines had been lost and the tegument was covered with numerous small blebs resulting in an eroded surface with lesions, which, after $12 \mathrm{~h}$ - had increased on both dorsal and ventral surfaces (fig. 5D-E). Numerous small perforations were found throughout the tegument, especially in the mid-body to posterior region. Similar changes occurred after $24 \mathrm{~h}$ and the apical plasma membrane completely disappeared from both surfaces, revealing empty spine sockets and loss of spines (fig. 5F). The tegumental surface changes were similar on both surfaces, with the anterior region of worms less damaged than the posterior region.

\section{Discussion}

The present study has shown that niclosamide is highly effective in killing adults of Haplorchis taichui in vitro at low concentrations. All worms become inactive after $1 \mathrm{~h}$ in $0.01 \mu \mathrm{g} \mathrm{ml}^{-1}$ and after $30 \mathrm{~min}$ in $0.1 \mu \mathrm{g} \mathrm{ml}^{-1}$ of niclosamide. This finding is similar to the effects of praziquantel on some trematodes such as Fibricola seoulensis (Lee, 1985) and Paragonimus westermani (Lee et al., 1987). It is suggested that niclosamide can kill intestinal flukes with high efficiency and can cure heterophyidiasis. In addition, niclosamide has been reported to cure some fluke infections such as Metagonimus yokogawai (Rim, 1975) Fasciolopsis buski (Suntharasamai et al., 1974) and Haplorchis taichui (Sukontason et al., 2000).

The present study has shown that niclosamide progressively causes severe disruption to the tegumental surface of $H$. taichui with longer exposure times. After $30 \mathrm{~min}$ to $6 \mathrm{~h}$ of exposure to $0.01 \mu \mathrm{g} \mathrm{ml}^{-1}$ and $30 \mathrm{~min}$ to $1 \mathrm{~h}$ in $0.1,1$ and $10 \mu \mathrm{g} \mathrm{ml}^{-1}$ niclosamide, morphological changes were observed in the anterior region, especially around the oral sucker and ventrogenital sac of the fluke. Various-sized blebs developed in the area between the oral sucker and ventrogenital sac. After $6 \mathrm{~h}$ in $0.1,1.0$ and $10 \mu \mathrm{g} \mathrm{ml}^{-1}$ niclosamide, more severe disruption was evident in the posterior region. Movement and feeding of worms are disrupted since the drug penetrates the pharynx and the early part of the intestine whereas changes in the posterior region of the gut are more severe on exposure over a longer period of the incubation. 

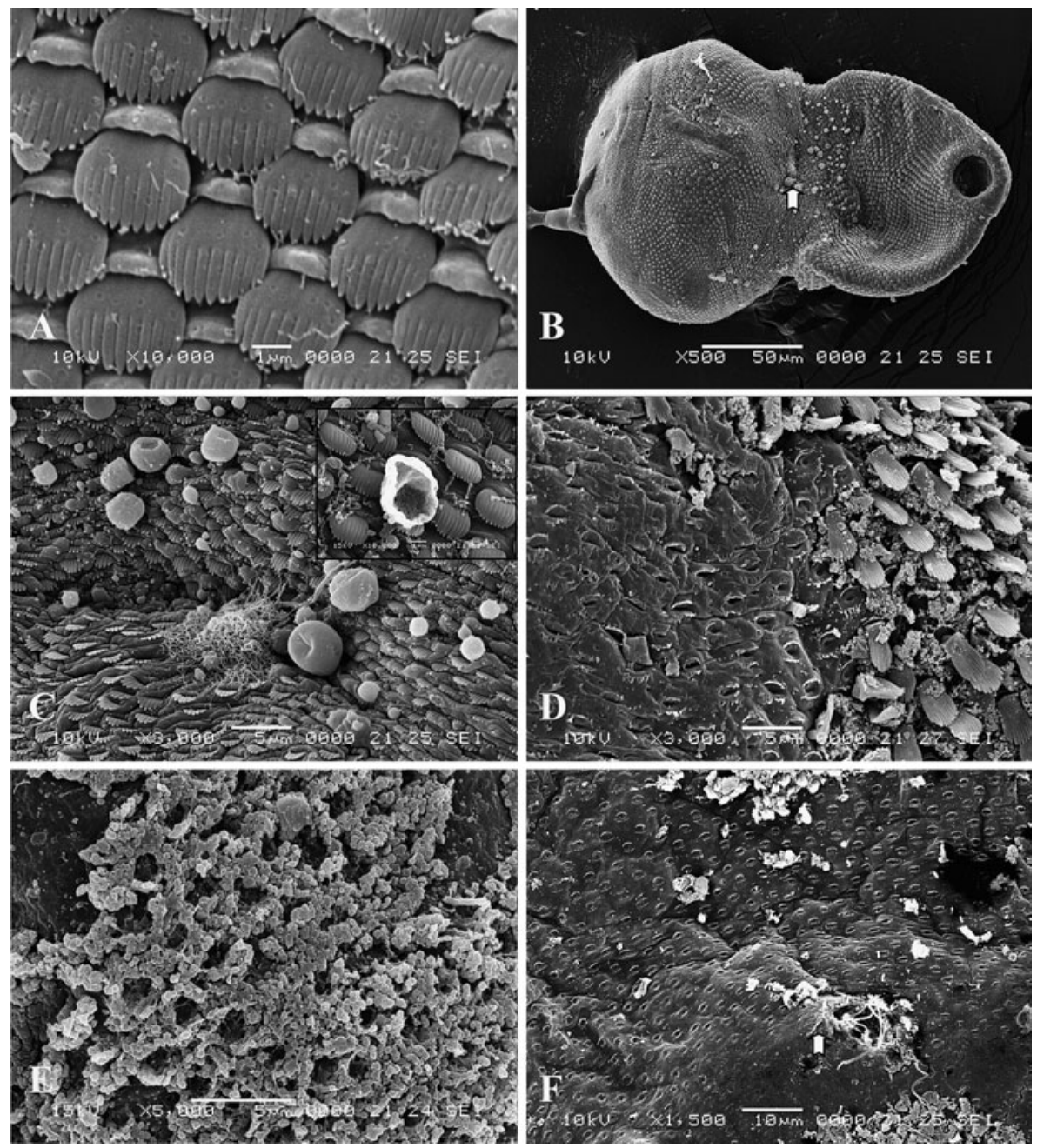

Fig. 3. Tegumental surface of adult Haplorchis taichui after treatment with $0.1 \mu \mathrm{g} \mathrm{ml}^{-1}$ niclosamide solution. A, Anterior region with swelling of tegument between the spines after $30 \mathrm{~min}(\times 10,000)$; B, spherical blebs more prominent above the ventrogenital sac (arrowed) after $1 \mathrm{~h}(\times 500)$; C, larger blebs and sunken spines appear after $1 \mathrm{~h}$, (inset, $\times 10,000)$ ruptured blebs occur after $6 \mathrm{~h}(\times 3000)$; , loss of spines on the mid-body surface and the appearance of spine sockets after $12 \mathrm{~h}(\times 3000)$; E, numerous blebs on the surface after $24 \mathrm{~h}$

$(\times 5000) ; \mathrm{F}$, loss of spines and the occurrence of spine sockets around the ventrogenital sac (arrowed) after $24 \mathrm{~h}(\times 1500)$.

The more rapid anterior blebbing is probably due to niclosamide being absorbed with great efficacy and over longer incubation times, worms become less active and finally immobile. Damage in the posterior region of worms is due to drug accumulation in the posterior part of the gut. The results support the concept that oral ingestion of niclosamide is the main route of entry, which agrees with the work of Meaney et al. $(2004,2005)$ on some fasciolicides. In addition, the rapid tegumental disruption observed in vitro is probably due to worms being in more direct contact with the drug. There is a more immediate effect of this drug via oral uptake and worms quickly become paralysed and rapidly killed (Fairweather et al., 1984; McKinstry et al., 2003). However, some drugs such as benzimidazoles can penetrate the tegument of the parasite with high efficiency. Mottier et al. (2006) reported that passive diffusion though the external helminth surface is a major mechanism of benzimidazole penetration into the trematode, Fasciola hepatica, the cestode, Moniezia benedeni and the nematode, Ascaris suum.

Regional differences in tegumental disruption were observed in treated $H$. taichui. The dorsal surface showed a similar disruption to the ventral surface and the posterior region was more severely disrupted than the anterior part. The findings are similar to the effects of praziquantel (Apinhasmit \& Sobhon, 1996), albendazole sulphoxide (Buchanan et al., 2003), and 5-chloro-2methylthio-6-(1-naphthyloxy)-1-H-benzimidazole(Rivera et al., 2004, 2005). The regional differences in damage may be due to tegumental structure, route of drug uptake and drug metabolism (McKinstry et al., 2003). The drug is more rapidly absorbed when worms are contacted in the earlier incubation times, resulting in the occurrence of various-sized blebs between the oral sucker and 

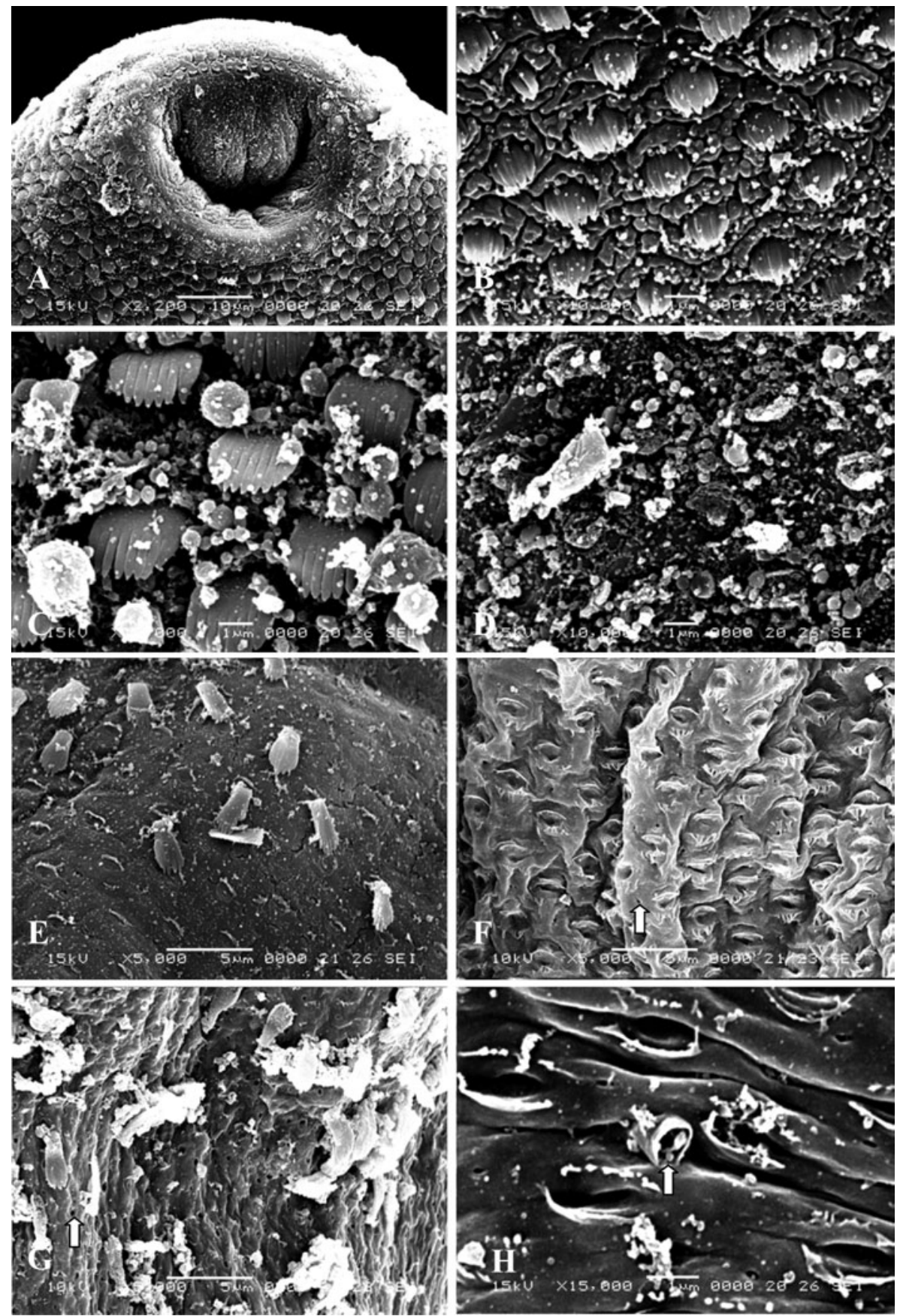

Fig. 4. Tegumental surface of adult Haplorchis taichui after incubation with $1.0 \mu \mathrm{g} \mathrm{ml}^{-1}$ niclosamide solution. A, Anterior region with numerous small blebs at $30 \mathrm{~min}(\times 2200)$; $\mathrm{B}$, posterior region with numerous blebs after $1 \mathrm{~h}(\times 10,000)$; , various size of blebs in anterior region after $6 \mathrm{~h}(\times 10,000)$; D, posterior region eroded with some loss of spines, and the surface covered with blebs after $6 \mathrm{~h}(\times 10,000)$; $\mathrm{E}$, spines lost with the appearance of spine sockets after $12 \mathrm{~h}(\times 5,000)$; F, loss of spines presence of spine sockets and small perforations (arrowed) on the basal lamina after $12 \mathrm{~h}(\times 5000)$; G, numerous small perforations (arrowed) on the basal lamina after $24 \mathrm{~h}(\times 5000)$; $\mathrm{H}$, sensory papillae (arrowed) ruptured after $24 \mathrm{~h}(\times 15,000)$.

ventrogenital sac. The anterior region is less damaged than posteriorly probably because this area is more densely covered with larger spines compared with smaller spines in the posterior region.
Surface blebbing and swelling of the tegument of $H$. taichui were observed after short exposure times. McKinstry et al. (2003) suggested that blebbing is an initial stress reaction by worms to replace the surface 

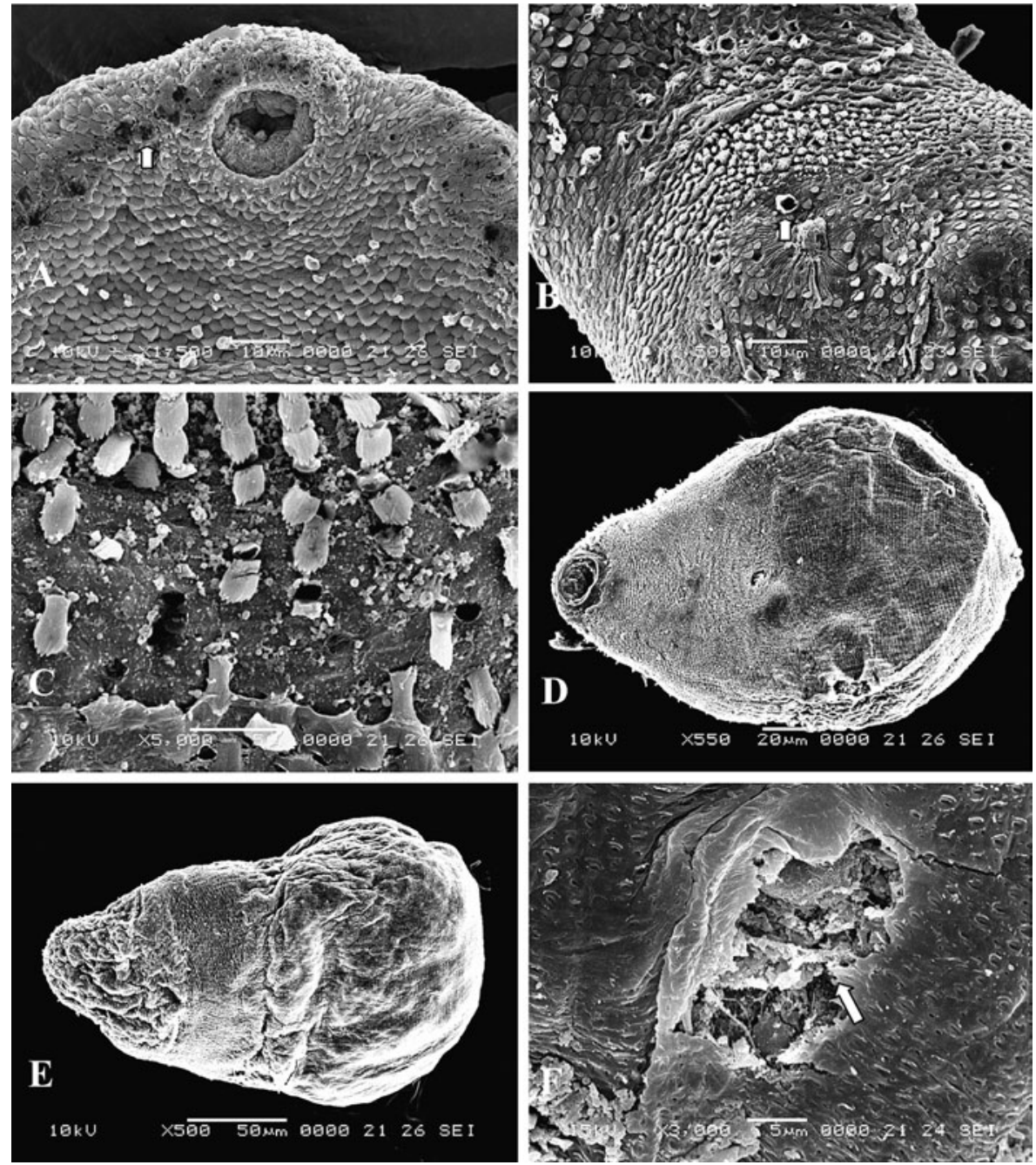

Fig. 5. Tegumental surface of adult Haplorchis taichui after incubation with $10.0 \mu \mathrm{g} \mathrm{ml}^{-1}$ niclosamide solution. A, Some blebs ruptured and lesions (arrowed) in the anterior region after $1 \mathrm{~h}(\times 1500)$; B, numerous blebs ruptured causing lesions (arrowed) after $1 \mathrm{~h}(\times 1500)$; $\mathrm{C}$, numerous blebs scattered on the tegument and loss of the plasma membrane in some regions after $6 \mathrm{~h}(\times 5000)$; $\mathrm{D}$, loss of spines on the ventral surface after $12 \mathrm{~h}(\times 550)$; E, loss of spines on the dorsal surface after $12 \mathrm{~h}(\times 500)$; F, complete loss the apical plasma membrane and some lesions (arrowed) after $24 \mathrm{~h}(\times 3000)$.

membrane. Similar observations were made for other anthelmintic drugs (Lee et al., 1987; Stitt \& Fairweather, 1993; Apinhasmit \& Sobhon, 1996; Meaney et al., 2002, 2003; Buchanan et al., 2003). Blebbing and swelling are early changes leading to loss of the tegument. It is suggested that the anthelmintic drug can penetrate into deeper-lying tissues, following breaching of the apical plasma membrane, thereby producing more severe worm disruption. Similar swelling of the tegument and blebbing, then rupturing and lesions, have been reported for praziquantel (Lee, 1985; Lee et al., 1987; Apinhasmit \& Sobhon, 1996). The swelling of the tegument is probably due to the disruption of ion pumps on the apical plasma membrane. This action decreases the production of ATP in the mitochondria and affects the ion pump, leading to an influx of water and swelling of the tegument (Skuce et al., 1987). When tegumental surface disruption becomes more severe, transport is disrupted throughout the syncytium so the plasma membrane cannot be replaced quickly enough to prevent separation of the tegument, leading to complete loss of the syncytium. The drug exposes the basal lamina and creates small perforations, then penetrates the internal tissues, causing greater worm damage with some lesions (Meaney et al., 2001). In the present study, blebs were formed on the tegumental surface of treated worms. The removal of the apical plasma membrane and spine sockets occurred on both surfaces. Surface destruction was more pronounced posteriorly than anteriorly with both surfaces. Numerous small perforations occurred posteriorly but fewer anteriorly. These findings suggest that worms exposed to niclosamide showed severe disruption, although further 
work using transmission electron microscopy are need to describe internal structural changes and confirm the route of drug transport.

\section{Acknowledgements}

This investigation was supported by BGJ Program no. BGJ 47K0010 and RGJ PhD Program no. PHD/0081/ 2544 from the Thailand Research Fund. The authors would like to thank Asoc. Prof. Dr Kom Sukontason, $\mathrm{Mr}$ Tanu Marayong, Mr Thanapon Yooyen, and colleagues in the Parasitology Research Laboratory Department of Biology, Faculty of Sciences, Chiang Mai University for their assistance. The Electron Microscopy Research and Service Center, Faculty of Science, Chiang Mai University, Chiang Mai, Thailand and the Electron Microscopy Research and Service Center, Seoul National University, Seoul, Korea, are gratefully thanked for electron microscopy facilities. Special thanks are given to Mrs Bussabong Kantalue, Mr Anantachai Kamsaiyai and $\mathrm{Mr}$ Sung-Yil Choi for their technical assistance in electron microscopic operation and photography.

\section{References}

Anon. (2003) Rat medication guide: niclosamide. [online] http://ratguide.com/meds/infectives/niclosamide. php. variable: 8 June 2005 .

Apinhasmit, W. \& Sobhon, P. (1996) Opisthorchis viverrini: effect of praziquantel on the adult tegument. Southeast Asian Journal of Tropical Medicine and Public Health 27, 304-311.

Buchanan, J.F., Fairweather, I., Brennan, G.P., Trudgett, A. \& Hoey, E.M. (2003) Fasciola hepatica: surface and internal tegumental changes induced by treatment in vitro with the sulphoxide metabolite of albendazole ('Valbazen'). Parasitology 126, 141-153.

Fairweather, I., Holmes, S.D. \& Threadgold, L.T. (1984) Fasciola hepatica: motility response to fasciolicides in vitro. Experimental Parasitology 57, 209-224.

Faust, E.C. \& Nishigori, M. (1926) The life cycles of two new species of Heterophyidae, parasitic in mammals and birds. Journal of Parasitology 13, 91-132.

Garcia, L.S. (2001) Diagnostic medicinal parasitology. 4th ed., pp. 413-444, Washington, DC, ASM Press.

Katz, M. (1986) Anthelmintics: current concepts in the treatment of helminthic infections. Drugs 32, 358-371.

Khalil, H.M. \& Rifaat, M.A. (1964) A further trial of 'Yomesan' in Heterophyes heterophyes infection. Journal of Tropical Medicine and Hygiene 62, 286-287.

Kliks, M. \& Tantachamrun, T. (1974) Heterophyid (Trematoda) parasites of cats in north Thailand, with notes on a human case found at necropsy. Southeast Asian Journal of Tropical Medicine and Public Health 5, 547-555.

Kumchoo, K., Wongsawad, C., Chai, J.Y., Vanittanakom, P. \& Rojanapaibul, A. (2005) High prevalence of Haplorchis taichui metacercariae in cyprinoid fish from Chiang Mai Province, Thailand. Southeast Asian Journal of Tropical Medicine and Public Health 36, 451-455.

Lee, S.H. (1985) In vitro effects of praziquantel on Fibricola seoulensis. Seoul Journal of Medicine 26, 41-51.
Lee, S.H., Park, H.J., Hong, S.J., Chai, J.Y. \& Hong, S.T. (1987) In vitro effect of praziquantel on Paragonimus westermani by light and scanning electron microscopic observation. Korean Journal of Parasitology 25, 24-36.

McKinstry, B., Fairweather, I., Brennan, G.P. \& Forbes, A.B. (2003) Fasciola hepatica: tegumental surface alterations following treatment in vivo and in vitro with nitroxynil (Trodax). Parasitology Research 91, $251-263$.

Meaney, M., Fairweather, I., Brennan, G.P., Ramasamy, P. \& Subramanian, P.B. (2001) Fasciola hepatica: tegumental surface alterations following treatment in vitro with the sulphoxide metabolite of triclabendazole. Parasitology Research 88, 315-325.

Meaney, M., Fairweather, I., Brennan, G.P., Ramasamy, P. \& Subramanian, P.B. (2002) Fasciola gigantica: tegumental surface alterations following treatment in vitro with the sulphoxide metabolite of triclabendazole. Parasitology Research 88, 315-325.

Meaney, M., Fairweather, I., Brennan, G.P., McDowell, L.S.L. \& Forbes, A.B. (2003) Fasciola hepatica: effects of the fasciolicide clorsulon in vitro and in vivo on the tegumental surface, and a comparision of the effects on young and old mature flukes. Parasitology Research 91, $238-250$.

Meaney, M., Fairweather, I., Brennan, G.P. \& Forbes, A.B. (2004) Transmission electron microscope study of the ultrastructural changes induced in the tegument and gut of Fasciola hepatica following in vivo drug treatment with clorsulon. Parasitology Research 92, 232-241.

Meaney, M., Haughey, S., Brennan, G.P. \& Fairweather, I. (2005) A scanning electron microscope study on the route of entry of clorsulon into the liver fluke, Fasciola hepatica. Parasitology Research 95, 117-128.

Mottier, L., Alvarez, L., Ceballos, L. \& Lanusse, C. (2006) Drug transport mechanisms in helminth parasites: passive diffusion of benzimidazole anthelmimtics. Experimental Parasitology 113, 49-57.

Pungpak, S., Radomyos, P., Radomyos, B., Schelp, F.P., Jongsaksuntigul, P. \& Bunnag, D. (1998) Treatment of Opisthorchis viverrini and intestinal fluke infections with praziquantel. Southeast Asian Journal of Tropical Medicine and Public Health 29, 246-249.

Radomyos, B., Wongsaroj, T., Wilairatana, P., Radomyos, P., Praevanich, R., Meesomboon, V. \& Jongsuksuntikul, P. (1998) Opisthorchiasis and intestinal fluke infections in northern Thailand. Southeast Asian Journal of Tropical Medicine and Public Health 29, $123-127$.

Rim, H.J. (1975) Studies on the chemotherapy of trematode infections in Korea. Korean Medical Journal 2, 425-457 (in Korean).

Rivera, N., Ibarra, F., Zepeda, A., Fortoul, T., Hernandez, A., Castillo, R. \& Canto, G. (2004) Tegumental surface changes in adult Fasciola hepatica following treatment in vitro and in vivo with an experimental fasciolicide. Parasitology Research 93, 283-386.

Rivera, N., Ibarra, F., Zepeda, A., Fortoul, T., Canto, G., Hernandez, A. \& Castillo, R. (2005) The effect of the 5-chloro-2-methylthio-6-(1-naphthyloxy)-1H benzimidazole on the tegument of immature Fasciola hepatica in their natural host. Parasitology Research 95, 379-382. 
Schmahl, G. \& Taraschewski, H. (1987) Treatment of fish parasites. 2. Effects of praziquantel, niclosamide, levamisole- $\mathrm{HCl}$, and metrifonate on Monogenea (Gyrodactylus aculeati, Diplozoon paradoxum). Parasitology Research 73, 341-351.

Scholz, T., Ditrich, O., Tuma, M. \& Giboda, M. (1991) Study of the body surface of Haplorchis yokogawai (Katsuta, 1932) and $H$. taichui (Nishigori, 1924) (Trematoda: Heterophyidae). Southeast Asian Journal of Tropical Medicine and Public Health 22, 443-448.

Skuce, P.J., Anderson, H.R. \& Fairweather, I. (1987) The interaction between the deacetylated (amine) metabolite of diamphenethide (DAMD) and cytochemically demonstrable $\mathrm{Na}^{+} / \mathrm{K}^{+}$-ATPase activity in th tegument of Fasciola hepatica. Parasitology Research 74, 161-167.

Srisawangwong, T., Sithithaworn, P. \& Tesana, S. (1997) Metacercariae isolated from cypriniod fishes in Khon Kaen District by digestion technique. Southeast Asian Journal of Tropical Medicine and Public Health 28 (suppl), 224-226.

Stitt, A.W. \& Fairweather, I. (1993) Fasciola hepatica: tegumental surface changes in adult and juvenile flukes following treatment in vitro with the sulphoxide metabolite of triclabendazole (Fasinex). Parasitology Research 79, 529-536.

Sukontason, K., Piangjai, S., Muangyimpong, Y., Sukontason, K., Methanitikorn, R. \& Chaithong, U.
(1999) Prevalence of trematode metacercariae in cyprinoid fish of Ban Pao district, Chiang Mai province northern Thailand. Southeast Asian Journal of Tropical Medicine and Public Health 30, 365-370.

Sukontason, K., Sukontason, K., Muanguimpong, Y. \& Piangjai, S. (2000) Treatment of Haplorchis taichui in Mus musculus mice. Experimental Parasitology 94, 48-50.

Sukontason, K., Sukontason, K., Muanguimpong, Y. \& Piangjai, S. (2005) Evidence of Haplorchis taichui infection as pathogenic parasite: three case reports. Scandinavian Journal of Infectious Diseases 37, 388-390.

Suntharasamai, P., Bunnag, D., Tejavanij, S. \& Harinasuta, T. (1974) Comparative clinical trials of niclosamide and tetrachlorethylene in treatment of Fasciolopsis buski infection. Southeast Asian Journal of Tropical Medicine and Public Health 5, 556-559.

Waikagul, J., Nuamtanong, S. \& Visiadsuk, K. (2003) A preliminary study on the efficacy of albendazole against Haplorchis taichui: an intestinal trematode. Journal of Tropical Medicine and Parasitology 26, 98-99.

Yamaguti, S. (1958) The digenetic trematodes of vertebrates. Vol I, New York, Interscience Publishers New York.

(Accepted 13 September 2006) (C) 2007 Cambridge University Press 